\title{
Antimicrobial Multi-Resistance of Acinetobacter baumanii Isolated from Clinical Specimens in Douala (Cameroon)
}

\author{
Cecile Okalla Ebongue ${ }^{1,2, *}$, Emmanuel Roddy Mengue ${ }^{1,3}$, Jean-Pierre Nda Mefo'o ${ }^{1,2}$, \\ Martial Dongmo Tsiazok ${ }^{2}$, Raymond N'guessan Kouassi ${ }^{4}$, Elisabeth Ngo Bum ${ }^{5}$ \\ ${ }^{1}$ Clinical biology Laboratory, General Hospital of Douala, Douala, Cameroon \\ ${ }^{2}$ Department of Biological Sciences, Faculty of Medicine, University of Douala, Douala, Cameroon \\ ${ }^{3}$ Department of Biomedical Sciences, Faculty of Science, University of Ngaoundere, Ngaoundere, Cameroon \\ ${ }^{4}$ Department of Biological Sciences, Faculty of Medicine, University of Cocody, Abidjan, Ivory Cost \\ ${ }^{5}$ Department of Biological Sciences, Faculty of Science, University of Ngaoundere, Ngaoundere, Cameroon
}

\section{Email address}

cecileokalla@yahoo.fr (C. O. Ebongue)

\section{To cite this article:}

Cecile Okalla Ebongue, Emmanuel Roddy Mengue, Jean-Pierre Nda Mefo'o, Martial Dongmo Tsiazok, Raymond N'guessan Kouassi, Elisabeth Ngo Bum. Antimicrobial Multi-Resistance of Acinetobacter baumanii Isolated from Clinical Specimens in Douala (Cameroon). Journal of Diseases and Medicinal Plants. Vol. 1, No. 2, 2015, pp. 31-36. doi: 10.11648/j.jdmp.20150102.12

\begin{abstract}
Bacteria of the genus Acinetobacter are non-fermentative gram-negative bacilli, often considered as ubiquitous and frequently found in the environment. This work aimed to study the susceptibility of Acinetobacter baumannii isolated at the General Hospital of Douala. This bacterium, which is greatly involved in human pathology, demonstrated high innate and acquired resistance to multiple antibiotics classes. This was a descriptive and retrospective study over a period of ten years (2005-2014), covering all the isolates of Acinetobacter baumannii from in and out patients. Samples were analyzed in the bacteriology laboratory at the General Hospital of Douala. Data collection was made by extraction of the results of all susceptibility of Acinetobacter baumannii, carried out from 2005 to 2014, registered in the memory of the mini API ${ }^{\mathrm{TM}}$ system; this automated machine identifies and measures the susceptibility of all the bacterial strains. A total of 266 strains were isolated from suppurations, urine, urinary catheters, and all other specimens received by the laboratory during the study period. These strains obtained from samples collected from all services of the hospital and ambulatory patients. The resistance rates noted were: $67.29 \%$ for ticarcillin, $64.28 \%$ ticarcillin + clavulanic acid, $68.33 \%$ for piperacillin, 56.97 piperacillin + tazobactam, $58.27 \%$ ceftazidime, $58.01 \%$ cefepime, $21.05 \%$ imipenem, $33.46 \%$ colistin, $52.63 \%$ gentamicin, $48.49 \%$ tobramycin, $24.43 \%$ amikacin, $53.40 \%$ netilmicin, 50\% for ciprofloxacin and levofloxacin, $51.05 \%$ ofloxacin. The prevalence of multiresistant strains was $43.18 \%$, mostly seen in patients hospitalized in the Burns unit. Only imipenem and Amikacin showed good activity on these strains with $78.95 \%$ and $75.57 \%$ of susceptibility respectively. This study showed the low activity of penicillin even in combination with beta lactamases inhibitors, as well as the cephalosporins on strains of Acinetobacter baumannii. Therapeutic support of infections due to this pathogen is highly problematic in General hospital of Douala. However, imipenem and amikacin, and to a lesser extent colistin remains effective treatment choices.
\end{abstract}

Keywords: Acinetobacter baumannii, Multi-Drug Resistance, Antibiotics, Cameroon

\section{Introduction}

Bacteria of the genus Acinetobacter are non-fermentative Gram-negative bacilli, often considered as ubiquitous and frequently found in the environment $[1,2]$. These microorganisms, which are also part of the normal resident of healthy skin flora, have long been considered as contaminants of bacteriological samples, not responsible of infections [3].

Later, the Acinetobacter have proved their capacity to easily spread and become pathogenic with high epidemic risk particularly in hospitals, especially among fragile patients hospitalized in intensive care units [3,4,5]. The species $A$. baumannii is particularly involved, because it has the ability to survive on dry surfaces for prolonged periods of time whereby it can be easily spread [6]. A. baumannii is also capable to acclimatise to stress conditions, action of detergents, and antiseptics, and to develop multiple resistance mechanisms against the majority of antibiotics. This multidrug resistance explains the therapeutic difficulties when 
support for serious infections due to this pathogen, particularly in immunocompromised patients, those with serious underlying diseases, and those subjected to invasive procedures and treated with broad-spectrum antibiotics $[7,8,9]$.

In recent years, the rate of resistance growing of this pathogen in a wide range of antibiotics cause of serious therapeutic and clinical problems, leading to increased morbidity and mortality $[10,11,12]$. Microbiological surveillance is important for obtaining useful information for doctors in the empirical choice of antibiotics. The aim of this study was to determine the epidemiology and the susceptibility to antibiotics of the Acinetobacter, in order to limit the cost of support, and set up a suitable antibiotic therapy and appropriate preventive measures.

\section{Material and Methods}

This was a transversal descriptive study, carried out in the clinical biology laboratory of the General Hospital of Douala (Cameroon), and concerning all strains of Acinetobacter isolated from 2005 to 2014 (10 years). This multidisciplinary laboratory receives samples from outpatients and inpatients in various hospital services.

Sampling: all the isolates of $A$. baumannii obtained from diagnostic referred specimens (urine, genital samples, suppurations, blood, probes, catheter and puncture fluids) from ambulatory and in-patient received during the study period were included.

The strains considered as contaminants, as well as strains with incomplete susceptibility data were excluded.

For identification of Acinetobacter baumannii and the susceptibility tests to antibiotics, the urine samples were cultured on Cystine Lactose Electrolyte Deficient (CLED) agar, and the other specimens on Eosin Methylene Blue (EMB) agar; and incubated for 24 hours at $37^{\circ} \mathrm{C}$. The macroscopic colony appearance were observed (shape, size, color) and biochemical and enzymatic identification were performed using the ID $32 \mathrm{GN}^{\circledR}$ galleries, followed by automatic colorimetric reading on mini APITM (bio Mérieux SA, Marcy l'Étoile, France) after a period of 24 hours incubation at $37^{\circ} \mathrm{C}$. The susceptibility tests were performed using the dilution technique on ATBPSE $^{\circledR}$ galleries, and followed by automatic turbidi-nephelometric reading after 18 to 24 hours incubation. The results were expertise by the mini APITM system according to the breakpoints of the Committee of the Antibiogram of the French Society of Microbiology (CASFM) [13]. The following antibiotics molecules were studied in the ATB PSE ${ }^{\circledR}$ Gallery: Ticarcillin (TIC); Ticarcillin + clavulanic acid (TTC); Piperacillin (PIP); Piperacillin + tazobactam (TZP); Ceftazidime (CAZ); Cefepime (FEP); Imipenem (IMI); Meropenem (MERO); Gentamicin (GEN); Tobramycin (TOB); Amikacin (AKN); Netilmicin (NET); Ofloxacin (OFL); Ciprofloxacin (CIP); Levofloxacin (LVX); Colistin (COL); Fosfomycin (FOS); Sulfamethoxazole + trimethoprim (TSU); Rifampicin (RFA). All antibiotics were not been tested with the same frequency.

\subsection{Multidrug Resistant (MDR) Bacteria}

Bacterial strain was defined as multiresistant if it shows non-susceptibility to at least one agent in at least 3 antimicrobial categories of specific antibiotics active on this species [14]. Only major active antibiotics on Acinetobacter baumannii were considered in the profiling of multiresistant germs (ceftazidime, cefepime, imipenem, gentamicin, tobramycin, amikacin, netilmicin, ofloxacin, ciprofloxacin, levofloxacin, colistin).

Data collection consisted of the extraction of all the susceptibility results of Acinetobacter baumannii, carried out from 2005 to 2014 registered in the memory of the automatic miniAPI ${ }^{\mathrm{TM}}$ system (Excel format). These results included, the identification number, the date of isolation, the identified germ, the nature of the specimen, as well as antibiotics tested with their susceptibility profile ("S" for sensitive, "I" for intermediate, "R" for resistant). These data were supplemented by the service of origin of the specimen through the registers of the laboratory.

\subsection{Data Processing and Statistical Analysis}

In the calculation of the percentages of resistance, the "intermediary" results were included in the category "resistant". The descriptive analysis of the data was made using the software Epi info version 11 and Microsoft Excel 2010 .

\subsection{Ethical Considerations}

We obtained the authorisation of the Ethics Committee of the General Hospital of Douala.

Limits: the specific tests for detection of beta lactamases expanded spectrum (ESBL), ampC cephalosporinase, metallobetalactamase (MBL) production was not performed. Prior antibiotic taken by patient was unknown.

\section{Results}

\subsection{Strains Isolated}

During the years 2005 to 2014, a total of 6978 nonrecurring pathogenic strains have been isolated from all diagnostic referred specimens received by the laboratory of the General hospital. Among these strains, 1934 were nonfermentative Gram-negative (NFGN) bacilli and 266 were of Acinetobacter baumannii, representing $3.8 \%$ of all the isolates and $27.4 \%$ of the NFGN. Strains isolated were mostly suppurations $(37.22 \%)$, urine $(28.58 \%)$ and urinary catheters $(19.54 \%)$. A total of 77 strains were isolated from outpatients $(28.94 \%)$ followed by the patients hospitalized in the Department of surgery $(20.30 \%)$.

\subsection{Susceptibility to Antibiotics}

Resistance to the active betalactamines on A. baumannii strains was high for all of the molecules used, and always greater than $60 \%$, even when these molecules were used 
singly or in combination with beta lactamases inhibitors (Table 1). The most active aminoglycoside was amikacin (Table 1). The best therapeutic choices were amikacin and imipenem (Table 1). The average prevalence of the multi resistance in Acinetobacter baumannii strains was $43.18 \%$
(Table 2). These strains resistant to at least one representative of 3 classes of antibiotics were $49.01 \%$ intensive care unit, $44.68 \%$ internal medicine and $62.96 \%$ surgery (Table 3). Multi-resistant strains isolated from urinary catheter and suppurations were $63.46 \%$ and $51.51 \%$ respectively (Table 2 ).

Table 1. Antimicrobial resistance of A baumannii.

\begin{tabular}{llll}
\hline Antimicrobial category & Antimicrobial agent & $\mathbf{N}^{\circ}$ isolates (n/N) & Rate of resistance \\
\hline & TIC & $179 / 266$ & $171 / 266$ \\
& TCC & $177 / 259$ & 64.29 \\
Penicillin + Blactamase inhibitors & PIP & $147 / 258$ & 68.33 \\
& TZP & $155 / 266$ & 56.97 \\
Extended spectrum cephalosporins & CAZ & $152 / 262$ & 58.27 \\
Carbapenems & FEP & $56 / 266$ \\
& IMI & $140 / 266$ \\
Aminoglycosides & GEN & $129 / 266$ \\
& TOB & $65 / 266$ \\
& AKN & $102 / 191$ \\
Fluoroquinolones & NET & $97 / 190$ \\
& OFL & $133 / 266$ \\
Polymyxins & CIP & $107 / 214$ \\
Rifamycines & LEV & $86 / 257$ \\
\hline
\end{tabular}

$\mathrm{N}=$ total tested $\mathrm{n}=$ total resistant

$\mathrm{TIC}=$ Ticarcillin; TTC $=$ Ticarcillin + clavulanic acid $; \mathrm{PIP}=$ Piperacillin; TZP = Piperacillin + tazobactam; $\mathrm{CAZ}=\mathrm{Ceftazidime} ; \mathrm{FEP}=\mathrm{Cefepime} ; \mathrm{IMI}=$ Imipenem; MERO = Meropenem; GEN = Gentamicin; TOB = Tobramycin; AKN = Amikacin; NET = Netilmicin; OFL = Ofloxacin; CIP = Ciprofloxacin; LVX = Levofloxacin; COL = Colistin; FOS = Fosfomycin; TSU = Sulfamethoxazole + trimethoprim; RFA = Rifampicin.

Table 2. Multiresistance in different specimens.

\begin{tabular}{lll}
\hline Specimen & Total isolates n (\%) & MDR rate n (\%) \\
\hline Suppurations & $99(37.22)$ & $51(51.51)$ \\
Urine & $76(28.58)$ & $21(27.63)$ \\
Urinary catheter & $52(19.54)$ & $33(63.46)$ \\
Central venous catheter & $24(9.02)$ & $11(45.83)$ \\
Blood culture & $9(3.39)$ & $2(22.22)$ \\
Genital specimens & $3(1.12)$ & 0 \\
Probes & $2(0.75)$ & 0 \\
Pleural fluid & $1(0.38)$ & 0 \\
TOTAL & $266(100)$ & $118(43.18)$ \\
\hline
\end{tabular}

Table 3. Multiresistance in services.

\begin{tabular}{lll}
\hline Service & Total isolates n (\%) & MDR rate n (\%) \\
\hline Surgery & $54(20.30)$ & $34(62.96)$ \\
Intensive care unit & $51(19.18)$ & $25(49.01)$ \\
Internal Medicine & $47(17.67)$ & $21(44.68)$ \\
Burns Unit & $18(6.77)$ & $13(72.22)$ \\
Paediatrics & $9(3.39)$ & $2(22.22)$ \\
Gynaecology & $8(3.00)$ & $4(50.00)$ \\
Neonatology & $2(0.75)$ & $0(0.00)$ \\
External & $77(28.94)$ & $19(24.67)$ \\
Total & $266(100)$ & $118(43.18)$ \\
\hline
\end{tabular}

\section{Discussion}

A. baumannii has a prevalence of $3.81 \%$ of all the isolates in 10 years, less than Pseudomonas aeruginosa, the most isolated non-fermentative gram-negative bacilli in bacteriology laboratory of General Hospital of Douala. This is in agreement with data from the literature $[15,16]$. The prevalence of $A$. baumannii in our study is also less than that of Njall carried out at the Laquintinie hospital ICU, and results of ICU in France, which were 12\% and $14.4 \%$ respectively [17, 18]. Higher rates (19.1\%) were found in another study in Benin [19].

The majority of these strains came from suppurations, urine and urinary catheters. Bharath Lexan in Madagascar isolated $88.6 \%$ of the strains of Acinetobacter baumannii in suppurations, urine and respiratory specimens [20]. In our sample, respiratory specimens were little represented, which can lead to an under-estimation of the prevalence, especially in the ICU in intubated patients.

Multidrug resistance was observed for $43.18 \%$ of isolates, especially surgery, which was not the case elsewhere, where this phenomenon occurs especially in the intensive care unit $[21,22]$. Vladimir Krcmery isolated $66 \%$ of multi-resistant strains of central venous catheters, which was close enough to our study [23].

This phenomenon was $97.5 \%$ in an intensive care in Italy, $100 \%$ in an intensive care unit in Pakistan, $56 \%$ in a study in Slovakia, $72 \%$ in a Department of surgery in the United States. These rates varying, but overall very high (greater than $50 \%$ ) bear witness to the rapid spread of strains, and can justify the severity of infections with Acinetobacter baumannii [22, 23, 24, 25].

We observed high rates of multidrug resistant strains of Acinetobacter baumannii in the beta-lactams with a resistance rate still above $50 \%$ (59.97 to $67.29 \%$ ). Gangoue's rate in Central hospital in Cameroon was already $62 \%$ for ceftazidime, the Morocco and Tunisia resistance by $50 \%$ and $60 \%$ respectively in blood cultures $[26,27,28]$. In Belgium, this rate of resistance varies from $35.1 \%$ to $46.5 \%$ in the regions of Flanders, Wallonia and Brussels [29]. 
Indeed these cephalosporins are the most commonly used antibiotics in the HGD.

Our study also shows higher activity of amikacin compared to other aminoglycosides, which is $24.43 \%$ of resistant strains. This can be explained by the fact that this molecule is little used in this hospital. Data from the literature postulate that this molecule loses over the years its effectiveness on the strains of Acinetobacter baumannii [15, $16,30,31]$.

Concerning fluoroquinolones, the rates of resistance of the strains of Acinetobacter baumannii (50\%) were high as in the other African studies [27, 28].

The low activity of cephalosporins and fluoroquinolones in our study only serves to confirm the general tendency of the behaviour of these molecules to face multi-resistant strains [20, 24, 32, 33].

Imipenem showed good activity in strains of Acinetobacter baumannii. But increasingly imipenem demonstrated a decrease in its activity especially in the intensive care units or as part of the related infections in healthcare [21, 30, 31, 34, $35]$. Our rates are very high (21.05) compared with the study of Goly in Spain and an investigation in Belgium that were respectively $0 \%$ and $8.7 \%$ resistant strains $[29,36]$.

Some studies have also shown good activity of amikacin on multi-resistant strains of Acinetobacter baumannii [32].

The strains tested showed level of $33.46 \%$ resistance to colistin. The good in vitro activity of this molecule is found elsewhere [32, 37, 38]. Colistin in particular is often the last resort in many African health institutions, European and American [20, 24, 32, 39].

Rates of susceptibility to all the molecules at the General hospital of Douala, is still far below the average. These multi-resistant strains are a genuine therapeutic problem. Indeed at the General Hospital in Douala, only amikacin and imipenem retain a good activity.

It is necessary to implement quickly the measures for preserving the effectiveness of these molecules that are expensive and which usually constitute the last therapeutic lines.

\section{Conclusion}

This study has shown the low activity of penicillin even in combination with beta lactamases inhibitors, as well as the cephalosporins on strains of Acinetobacter baumannii. Therapeutic support of pathogenic infections is very problematic in the General Hospital of Douala. Imipenem and amikacin, to a lesser extent colistin remains the effective treatment choices. High rates of antibiotic resistance should at least impose a bi-antibiotherapy for fighting against infections due to this pathogen, and an exclusion of the betalactams in the treatment when multi-resistant strain is suspected. This high strength affects both the community and nosocomial isolates without significant difference and is variable depending on the services and specimens.

\section{Contribution of Authors}

COE, ERM and MDT participated in the collection and analysis of data. JPNM and RN have analyzed and interpreted the data. NB coordinated the study. The manuscript was designed by $\mathrm{COE}$ and all authors have contributed to the revision and approved the final version.

\section{References}

[1] Morgan, D. J., Rogawski, E., Thom, K. A., Johnson, J. K., Perencevich, E. N., Shardell, M. , \& Harris, A. D. (2012). Transfer of multidrug-resistant bacteria to healthcare workers' gloves and gowns after patient contact increases with environmental contamination. Critical care medicine, 40(4), 1045 .

[2] Thom KA, Johnson JK, Lee MS, Harris AD. Environmental Contamination due to Multidrug-resistant Acinetobacter baumannii surrounding Colonized or Infected Patients. Am J Infect Control. 2011;39(9):711-5.

[3] Decré, D. (2012). Acinetobacter baumannii et résistance aux antibiotiques: un modèle d'adaptation. Revue Francophone des Laboratoires, 2012(441), 43-52.

[4] Naas, T., Coignard, B., Carbonne, A., Blanckaert, K., Bajolet, O., Bernet, C., ... \& Nordmann, P. (2006). VEB-1 extendedspectrum $\beta$-lactamase-producing Acinetobacter baumannii, France. Emerging infectious diseases, 12(8), 1214.

[5] Arsalane, L., Qamouss, Y., Chafik, A., Boughalem, M., \& Louzi, L. (2010). Epidémiologie des bactéries multi résistantes dans un service de réanimation polyvalente d'un hôpital universitaire de Marrakech entre octobre 2006 et septembre 2009. Les technologies de laboratoire, 5(21).

[6] Peleg AY, Seifert H, Paterson DL. Acinetobacter baumannii: emergence of a successful pathogen. Clin Microbiol Rev 2008; 21: $538-82$.

[7] Fiester, S. E., \& Actis, L. A. (2013). Stress responses in the opportunistic pathogen Acinetobacter baumannii. Future microbiology, 8(3), 353-365.

[8] Gupta, V., Garg, R., Garg, S., Chander, J., \& Attri, A. K. (2013). Coexistence of extended spectrum beta-lactamases, AmpC beta-lactamases and metallo-beta-lactamases in Acinetobacter baumannii from burns patients: a report from a tertiary care centre of India. Annals of burns and fire disasters, 26(4), 189.

[9] Bonomo, R. A., \& Szabo, D. (2006). Mechanisms of multidrug resistance in Acinetobacter species and Pseudomonas aeruginosa. Clinical Infectious Diseases, 43(Supplement 2), S49-S56.

[10] Nicolay, N., Thiolet, J. M., Talon, D., Poujol, I., Bernet, C., Carbonne, A., ... \& Coignard, B. (2008). Signalement des infections nosocomiales à Pseudomonas aeruginosa, France, Août 2001-Juin 2006. Bull Epidemiol Hebd, 30-31.

[11] Sunenshine, R. H., Wright, M. O., Maragakis, L. L., Harris, A. D., Song, X., Hebden, J., ... \& Srinivasan, A. (2007). Multidrug-resistant Acinetobacter infection mortality rate and length of hospitalization. Emerging infectious diseases, 13(1), 97. 
[12] Lee, Y. T., Kuo, S. C., Yang, S. P., Lin, Y. T., Tseng, F. C., Chen, T. L., \& Fung, C. P. (2012). Impact of appropriate antimicrobial therapy on mortality associated with Acinetobacter baumannii bacteremia: relation to severity of infection. Clinical infectious diseases, 55(2), 209-215.

[13] Soussy CJ. Comité d'antibiogramme de la société francaise de microbiologie: récommandation 2011. 2011.

[14] Magiorakos, A. P., Srinivasan, A., Carey, R. B., Carmeli, Y., Falagas, M. E., Giske, C. G., ... \& Monnet, D. L. (2012). Multidrug - resistant, extensively drug - resistant and pandrug - resistant bacteria: an international expert proposal for interim standard definitions for acquired resistance. Clinical Microbiology and Infection, 18(3), 268-281.

[15] Memish, Z. A., Shibl, A. M., Kambal, A. M., Ohaly, Y. A., Ishaq, A., \& Livermore, D. M. (2012). Antimicrobial resistance among non-fermenting Gram-negative bacteria in Saudi Arabia. Journal of antimicrobial chemotherapy, 67(7), 1701-1705.

[16] Patel, P. H., Pethani, J. D., Rathod, S. D., Chauhan, B., \& Shah, P. D. (2013). Prevalence of nonfermenting Gram negative bacilli infection in tertiary care Hospital in Ahmedabad, Gujarat. Indian Journal of Basic \& Applied Medical Research, 2(6), 608-613.

[17] Njall, C., Adiogo, D., Bita, A., Ateba, N., Sume, G., Kollo, B., ... \& Tchoua, R. (2013). Écologie bactérienne de l'infection nosocomiale au service de réanimation de l'hôpital Laquintinie de Douala, Cameroun. The Pan African Medical Journal, 14.

[18] Réseau, R. E. A. Raisin. Surveillance des infections nosocomiales en réanimation adulte: Résultats 200 France: Institut de veille sanitaire, sept. 2009; 60p. PubMed| Google Scholar.

[19] Ahoyo, T. A., Bankolé, H. S., Adéoti, F. M., Gbohoun, A. A., Assavèdo, S., Amoussou-Guénou, M., ... \& Pittet, D. (2014). Prevalence of nosocomial infections and anti-infective therapy in Benin: results of the first nationwide survey in 2012. Antimicrobial resistance and infection control, 3(1), 1-6.

[20] Andriamanantena, T. S., Ratsima, E., Rakotonirina, H. C., Randrianirina, F., Ramparany, L., Carod, J. F., ... \& Talarmin, A. (2010). Dissemination of multidrug resistant Acinetobacter baumannii in various hospitals of Antananarivo Madagascar. Annals of clinical microbiology and antimicrobials, 9(1), 17.

[21] Kuo, S. C., Chang, S. C., Wang, H. Y., Lai, J. F., Chen, P. C., Shiau, Y. R., ... \& Lauderdale, T. L. Y. (2012). Emergence of extensively drug-resistant Acinetobacter baumannii complex over 10 years: nationwide data from the Taiwan Surveillance of Antimicrobial Resistance (TSAR) program. BMC infectious diseases, 12(1), 200.

[22] Begum, S., Hasan, F., Hussain, S., \& Shah, A. A. (2013). Prevalence of multi drug resistant Acinetobacter baumannii in the clinical samples from Tertiary Care Hospital in Islamabad, Pakistan. Pakistan journal of medical sciences, 29(5), 1253.

[23] Krcmery, V., \& Kalavsky, E. (2007). Multidrug-resistant Acinetobacter baumannii. Emerging infectious diseases, 13(6), 943.

[24] Capone, A., D’Arezzo, S., Visca, P., \& Petrosillo, N. (2008). In vitro activity of tigecycline against multidrug-resistant Acinetobacter baumannii. Journal of antimicrobial chemotherapy, 62(2), 422-423.
[25] Dent, L. L., Marshall, D. R., Pratap, S., \& Hulette, R. B. (2010). Multidrug resistant Acinetobacter baumannii: a descriptive study in a city hospital. BMC infectious diseases, 10(1), 196.

[26] Gangoue-Pieboji, J., Koulla-Shiro, S., Ngassam, P., Adiogo, D., \& Ndumbe, P. (2007). Antimicrobial activity against gram negative bacilli from Yaounde Central Hospital, Cameroon. African health sciences, 6(4).

[27] Soraa N, Zougaghi L, Zahlane K, Admou B, Haouach K, Kachach M, et al. Épidémiologie et profil de sensibilité des isolats d'hémoculture dans un Centre Hospitalo Universitaire Marocain. Revue Tunisienne d'Infectiologie. 2011;5(2):78 - 81.

[28] Haj Khalifa AB, Khedher M. Fréquence et profil de sensibilité aux antibiotiques des bactéries isolées des hémocultures au CHU de Mahdia. Revue Tunisienne d'Infectiologie. 2010;4(3):92 - 5 .

[29] Jans B, Glupczynski Y. Enquête épidémiologique sur Acinetobacter baumannii et Pseudomonas aeruginosa dans les hôpitaux aigus en Belgique : Données pour l'année 2008. In: d'Epidémiologie ISdSPS, editor. 14, rue Juliette Wytsman 1050 Bruxelles - Belgique: Jans Béatrice; 2009.

[30] Xu, T., Xia, W., Rong, G., Pan, S., Huang, P., \& Gu, B. (2013). A 4-year surveillance of antimicrobial resistance patterns of Acinetobacter baumanni in a university-affiliated hospital in China. Journal of thoracic disease, 5(4), 506.

[31] Landman, D., Bratu, S., Kochar, S., Panwar, M., Trehan, M., Doymaz, M., \& Quale, J. (2007). Evolution of antimicrobial resistance among Pseudomonas aeruginosa, Acinetobacter baumannii and Klebsiella pneumoniae in Brooklyn, NY. Journal of antimicrobial chemotherapy, 60(1), 78-82.

[32] Ahmed, N. H., Baba, K., Clay, C., Lekalakala, R., \& Hoosen, A. A. (2012). In vitro activity of tigecycline against clinical isolates of carbapenem resistant Acinetobacter baumannii complex in Pretoria, South Africa. BMC research notes, 5(1), 215.

[33] Mansouri, S., Razavi, M., Norouzi, F., \& Najar, S. G. (2012). Prevalence of $\beta$-Lactamase Production and Antimicrobial Susceptibility of Multidrug Resistant Clinical Isolates of NonFermenting Gram Negative Bacteria From Hospitalized Patients in Kerman/Iran. Jundishapur Journal of Microbiology, 2012(2, Spring), 405-410.

[34] Bayram, A., \& Balci, I. (2006). Patterns of antimicrobial resistance in a surgical intensive care unit of a university hospital in Turkey. BMC infectious diseases, 6(1), 155.

[35] Vala, M. H., Hallajzadeh, M., Fallah, F., Hashemi, A., \& Goudarzi, H. (2013). Characterization of the ExtendedSpectrum beta-Lactamase Producers among Non-Fermenting Gram-Negative Bacteria Isolated from Burnt Patients. Archives of Hygiene Sciences, 2(1).

[36] Guembe, E., Mansilla, E. C., Alcalá, L., Soria, R. I., Bouza, E., \& Marín, M. (2008). Evolution of antimicrobial susceptibility patterns of aerobic and facultative gram-negative bacilli causing intra-abdominal infections: results from the SMART studies 2003-2007. Revista Española de Quimioterapia, 21(3), 166-173.

[37] Baadani, A. M., Thawadi, S. I., El-Khizzi, N. A., \& Omrani, A S. (2013). Prevalence of colistin and tigecycline resistance in Acinetobacter baumannii clinical isolates from 2 hospitals in Riyadh Region over a 2-year period. Saudi medical journal, 34(3), 248-253. 
[38] Morfin-Otero, R., Tinoco-Favila, J. C., Sader, H. S., Salcido-Gutierrez, L., Perez-Gomez, H. R., Gonzalez-Diaz, E., ... \& Rodriguez-Noriega, E. (2012). Resistance trends in gram-negative bacteria: surveillance results from two Mexican hospitals, 2005-2010. BMC research notes, 5(1), 277.
[39] Koomanachai, P., Tiengrim, S., Kiratisin, P., \& Thamlikitkul, V. (2007). Efficacy and safety of colistin (colistimethate sodium) for therapy of infections caused by multidrugresistant Pseudomonas aeruginosa and Acinetobacter baumannii in Siriraj Hospital, Bangkok, Thailand. International Journal of Infectious Diseases, 11(5), 402-406. 